Article

\title{
Synthesis and Application of Novel Magnetic Ion-Imprinted Polymers for Selective Solid Phase Extraction of Cadmium (II)
}

\author{
Xiaoyan $\mathrm{Xu}{ }^{1,2}$, Mei Wang ${ }^{1,2}$, Qing $\mathrm{Wu}^{1,2}$, Zhenlin $\mathrm{Xu}{ }^{1,2}$ and Xingguo Tian ${ }^{1,2, *}$ \\ 1 Guangdong Provincial Key Laboratory of Food Quality and Safety, South China Agricultural University, \\ Guangzhou 510640, Guangdong, China; yanzixu_2001@scau.edu.com (X.X.); wm303035@163.com (M.W.); \\ wuqing@scau.edu.cn (Q.W.); jallent@163.com (Z.X.) \\ 2 College of Food Science, South China Agricultural University, Guangzhou 510640, Guangdong, China \\ * Correspondence: xingguot@scau.edu.cn; Tel.: +86-020-8528-3433
}

Received: 4 July 2017; Accepted: 10 August 2017; Published: 14 August 2017

\begin{abstract}
Ion-imprinted polymers (IIPs) have received much attention in the fields of separation and purification. Nevertheless, selectivity of IIPs for trace target ions in complicated matrix remains a challenge. In this work, a cadmium magnetic ion-imprinted polymer (MIIP) was synthesized via surface imprinting, using methacrylic acid and acrylamide as dual functional monomers, vinyltrimethoxysilane as ligand, $\mathrm{Fe}_{3} \mathrm{O}_{4} @ \mathrm{SiO}_{2}$ as support, azodiisobutyronitrile as initiator, and ethylene glycol dimethacrylate as crosslinker. The MIIP was characterized by transmission electron microscopy, infrared spectroscopy, thermal gravimetric analysis, and a vibrating sample magnetometer. The maximum adsorption capacities of the MIIP and magnetic non-imprinted polymer for $\mathrm{Cd}(\mathrm{II})$ were 46.8 and $14.7 \mathrm{mg} \cdot \mathrm{g}^{-1}$, respectively. The selectivity factors of $\mathrm{Pb}(\mathrm{II}), \mathrm{Cu}(\mathrm{II})$, and $\mathrm{Ni}(\mathrm{II})$ were $3.17,2.97$, and 2.57 , respectively, which were greater than 1 . The adsorption behavior of Cd(II) followed the Freundlich isotherm and a pseudo second order model. The MIIP was successfully used for the selective extraction and determination of trace $\mathrm{Cd}(\mathrm{II})$ in representative rice samples. The limit of detection and recovery of the method was $0.05 \mu \mathrm{g} \cdot \mathrm{L}^{-1}$ and $80-103 \%$, respectively, with a relative standard deviation less than $4.8 \%$. This study shows that MIIP provides an attractive strategy for heavy metal detection.
\end{abstract}

Keywords: magnetic ion-imprinted polymers; cadmium ion; dual functional monomers; solid-phase extraction

\section{Introduction}

Cadmium is one of the most toxic heavy metals and causes serious harm to human health via the food chain [1,2]. The International Agency for Research on Cancer classified cadmium as a human carcinogen [3]. Therefore, developing reliable methods for the removal and determination of cadmium in food is important. A wide range of analytical techniques to evaluate cadmium(II) in the spiked or real samples have been reported in recent years, including atomic absorption spectrometry (AAS) [4], inductively coupled plasma mass spectrometry (ICP-MS) [5], electrochemical sensor [6]. Among them, atomic absorption spectrometry has been popular because of its simplicity, easy operation, and low cost [7]. However, its low sensitivity in trace analysis of complex systems largely limits its applications because of the matrix interferences [8]. Therefore, a suitable separation and preconcentration step such as solid-phase extraction is necessary for concentrating the target analytes from real samples [9].

Ion imprinting is a process in which co-polymerization has been performed between functional and cross-linking monomers in the presence of a target ion (the imprint ion) [10]. Extraction of the template molecules leaves a predetermined arrangement of ligands and a tailored binding pocket [11]. 
Now, ion-imprinted polymers (IIPs) are becoming promising solid-phase extraction (SPE) sorbents and have gained much attention because of their outstanding advantages such as high selectivity, large adsorption capacity, and good reusability [12,13]. Ghorbani et al. [14] successfully synthesized Pd(II) ion-imprinted polymers for selective extraction and determination in food and environmental samples. A Ni(II) ion-imprinted polymer prepared by Saraji et al. [15] was employed as a sorbent in a solid-phase extraction column to preconcentrate trace nickel with satisfactory results. However, complicated post-processing, such as filtration and centrifugation, are required when applying these ion-imprinted polymers [16]. If ion-imprinted polymer materials are chemically grafted onto $\mathrm{Fe}_{3} \mathrm{O}_{4}$ nanoparticles, which have unique magnetic properties and high surface area, easy separation and selective extraction can be achieved with the application of an external magnetic field. Previously published papers have shown a successful combination of ion-imprinted polymers and $\mathrm{Fe}_{3} \mathrm{O}_{4}$, and superior performance from magnetic imprinted polymers was reported compared with that of imprinted polymers without magnetic nanoparticles attached [17-19].

Despite the emerged interests in magnetic ion imprinting techniques, single functional monomers are widely and generally used for preparing imprinted polymers and thereby result in low selectivity. Thus, it has become quite imperative to develop new functional monomers and/or utilize dual/multiple functional monomers for improving the selective recognition capabilities and adsorption capacities of IIPs [20]. In the present work, a novel magnetic ion-imprinted polymer (MIIP) for Cd(II) was synthesized using dual functional monomers of MAA and acrylamide (AM) by surface imprinting. In addition, the characterization, kinetics, isotherm model of $\mathrm{Cd}(\mathrm{II})$ adsorption process, selectivity, and application of this new magnetic sorbent are discussed in this study.

\section{Materials and Methods}

\subsection{Reagents and Chemicals}

$\mathrm{Cd}, \mathrm{Pb}, \mathrm{Cu}$, and Ni reference solutions were supplied by Shanghai Macklin Biochemical Co., Ltd. (Shanghai, China), with a minimum $99 \%$ purity. All other reagents and chemicals including $\mathrm{FeCl}_{3} \cdot 6 \mathrm{H}_{2} \mathrm{O}$, $\mathrm{FeCl}_{2} \cdot 4 \mathrm{H}_{2} \mathrm{O}, \mathrm{PEG} 200, \mathrm{CdCl}_{2} \cdot 5 / 2 \mathrm{H}_{2} \mathrm{O}$, tetraethyl orthosilicate, vinyltrimethoxysilane, hexadecyl trimethyl ammonium bromide, methacrylic acid, acrylamide, ethylene glycol, dimethacrylate, and azodiisobutyronitrile were in analytical grade and purchased from Aladdin Industrial Corporation (Shanghai, China). Cd standard solution $\left(100 \mathrm{mg} \cdot \mathrm{L}^{-1}\right)$ was prepared by diluting a reference solution in $2 \%$ nitric acid solution. All of the solutions were stored in the fridge $\left(4{ }^{\circ} \mathrm{C}\right)$ and allowed to reach ambient temperature prior to use. The water used was ultrapure $(18.3 \mathrm{M} \Omega \cdot \mathrm{cm}$ resistivity).

\subsection{Characterization}

An AA800 graphite furnace atomic absorption spectrometer (Perkin Elmer, Shelton, CT, USA) was used to determine the concentration of metal ions $(\mathrm{Cd}, \mathrm{Ni}, \mathrm{Cu}$, and $\mathrm{Pb})$ in aqueous solution. The instrumental parameters were those recommended by the manufacturer. Hollow cathode lamps were used as the radiation sources. The wavelengths selected were 228.8, 232.0, 324.8, and $283.3 \mathrm{~nm}$ for Cd, $\mathrm{Ni}, \mathrm{Cu}$, and $\mathrm{Pb}$, respectively. A 780 digital $\mathrm{pH}$ Meter (Metrohm, Herisau, Switzerland), equipped with a combined $\mathrm{Ag} / \mathrm{AgCl}$ glass electrode was used for the $\mathrm{pH}$ adjustments at room temperature. Fourier transform infrared (FT-IR) spectra $\left(4000-500 \mathrm{~cm}^{-1}\right)$ were recorded using a Vertex 70 spectrometer (Bruker, Ettlingen, Germany) with $\mathrm{KBr}$ pellets and a resolution of $0.4 \mathrm{~cm}^{-1}$. Transmission electron microscope (TEM) images were acquired on a JEM-2100F instrument (JEOL, Peabody, MA, USA). Thermal gravimetric analysis (TGA) was performed on a TG209 F1 Libra instrument (Netzsch, Hanau, Germany) under argon atmosphere at a heating rate of $10{ }^{\circ} \mathrm{C} / \mathrm{min}$. Magnetic characteristics of $\mathrm{Fe}_{3} \mathrm{O}_{4}$ and MIIP were measured with an EZ7 vibrating sample magnetometer (MicroSense, Lowell, MA, USA) at $300 \mathrm{~K}$. 


\subsection{Preparation of Vinyl-Functionalized $\mathrm{Fe}_{3} \mathrm{O}_{4}$ Nanoparticles}

$\mathrm{Fe}_{3} \mathrm{O}_{4}$ nanoparticles were synthesized by the method of titration hydrolysis with minor modification [21]. Briefly, $0.02 \mathrm{~mol} \mathrm{FeCl} 3 \cdot 6 \mathrm{H}_{2} \mathrm{O}$ and $0.012 \mathrm{~mol} \mathrm{FeCl}_{2} \cdot 4 \mathrm{H}_{2} \mathrm{O}$ were dissolved in $100 \mathrm{~mL}$ of deionized water under a nitrogen atmosphere. This solution was subsequently heated to $80^{\circ} \mathrm{C}$ by a magnetic stirrer, followed by the addition of $15 \mathrm{~mL}$ of $\mathrm{NH}_{3} \cdot \mathrm{H}_{2} \mathrm{O}$ (32\% solution) and $2 \mathrm{~mL}$ of PEG200 sequentially. The resultant $\mathrm{Fe}_{3} \mathrm{O}_{4}$ nanoparticles were separated by a magnet, washed three times with ethanol and ultrapure water, and dried in a vacuum oven at $60^{\circ} \mathrm{C}$ overnight.

Vinyl modified $\mathrm{Fe}_{3} \mathrm{O}_{4}$ nanoparticles were performed as previously reported [22,23]. $\mathrm{Fe}_{3} \mathrm{O}_{4}$ nanoparticles $(0.5 \mathrm{~g}), 50 \mathrm{~mL}$ of anhydrous ethanol and $10 \mathrm{~mL}$ of $\mathrm{NH}_{3} \cdot \mathrm{H}_{2} \mathrm{O}$ were suspended in $100 \mathrm{~mL}$ of deionized water, and $2 \mathrm{~mL}$ of tetraethyl orthosilicate was added to the mixture dropwise. The $\mathrm{Fe}_{3} \mathrm{O}_{4} @ \mathrm{SiO}_{2}$ was obtained under stirring at room temperature after $6 \mathrm{~h}$. The $\mathrm{Fe}_{3} \mathrm{O}_{4} @ \mathrm{SiO}_{2}$ was dispersed in $100 \mathrm{~mL}$ of the mixture of water and ethanol $(1: 5, v / v)$. Ammonia water $(10 \mathrm{~mL})$ containing $2 \mathrm{~g}$ of hexadecyl trimethyl ammonium bromide, $4 \mathrm{~mL}$ of tetraethyl orthosilicate, and $3.7 \mathrm{~mL}$ of vinyltrimethoxysilane were added into the above mixture under vigorous stirring. After reaction at ambient temperature for $6 \mathrm{~h}$, the resultant products were refluxed in acetone solution at $80^{\circ} \mathrm{C}$ for $24 \mathrm{~h}$ to remove the hexadecyl trimethyl ammonium bromide.

\subsection{Preparation of Magnetic Cadmium Ion-imprinted Polymer}

The preparation of magnetic cadmium ion-imprinted polymer is schematically shown in Figure 1. Briefly, $0.5 \mathrm{mmol}$ of $\mathrm{CdCl}_{2} \cdot 5 / 2 \mathrm{H}_{2} \mathrm{O}, 1.5 \mathrm{mmol}$ of methacrylic acid, and $0.5 \mathrm{mmol}$ of acrylamide were dispersed into a mixture solution of acetonitrile $(40 \mathrm{~mL})$ and water $(10 \mathrm{~mL})$ under stirring at room temperature for $90 \mathrm{~min}$. Then $0.5 \mathrm{~g}$ of vinyl-modified $\mathrm{Fe}_{3} \mathrm{O}_{4} @ \mathrm{SiO}_{2}, 1.98 \mathrm{~g}$ of ethylene glycol dimethacrylate and $0.15 \mathrm{~g}$ of azodiisobutyronitrile were added consecutively. The polymerization reaction was performed at $85{ }^{\circ} \mathrm{C}$ with $10 \mathrm{~h}$ of stirring to obtain particles with a highly crosslinked structure. The product was separated with an external magnetic force, washed with ethanol, and oven-dried at $65{ }^{\circ} \mathrm{C}$ for $6 \mathrm{~h}$. The template was removed by $2.0 \mathrm{M}$ of $\mathrm{HCl}$. For comparison, magnetic non-imprinted polymer (MNIP) was also prepared using an identical procedure in the absence of the template (cadmium ions).

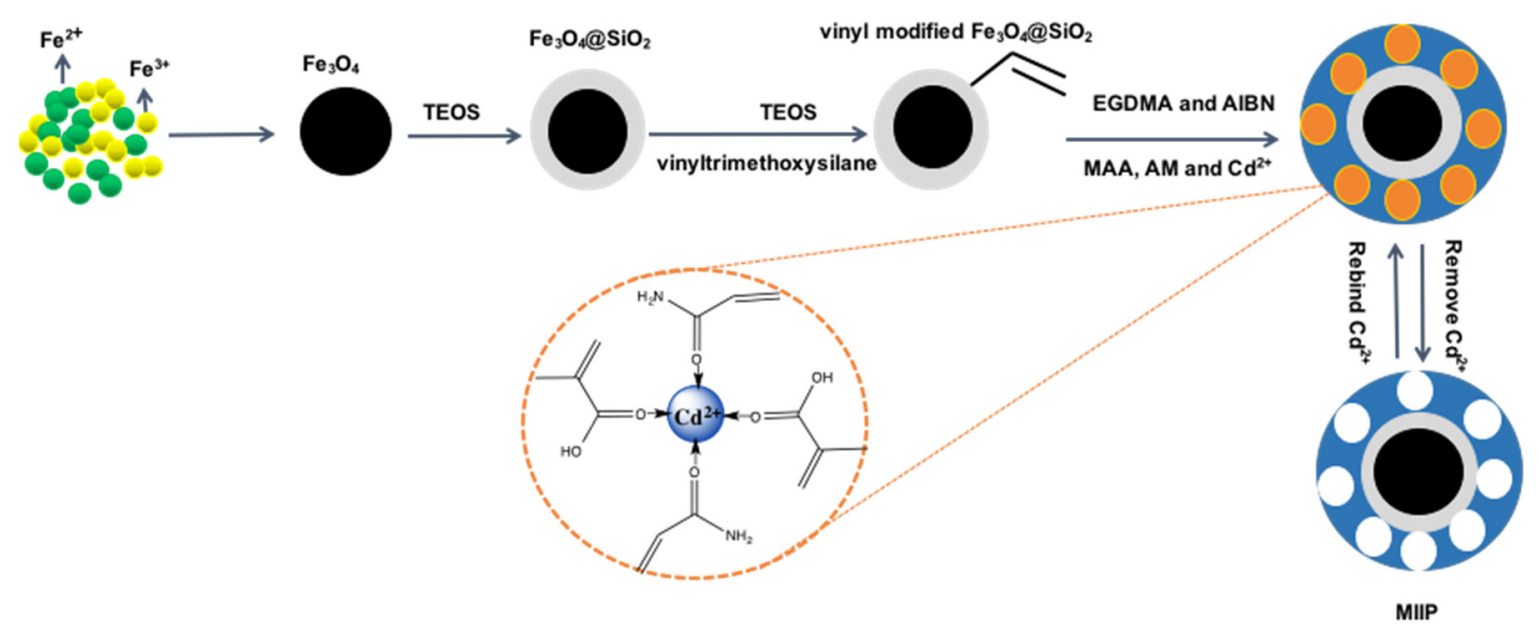

Figure 1. Schematic diagram for the preparation of magnetic ion-imprinted polymer (MIIP).

\subsection{Adsorption Experiments}

The adsorption of $\mathrm{Cd}(\mathrm{II})$ from aqueous solutions was investigated in batch experiments. The effect of $\mathrm{pH}$ on the adsorption capacity of the MIIP sorbents was studied with $20 \mathrm{~mL}$ of $70 \mu \mathrm{g} \cdot \mathrm{mL}^{-1}$ $\mathrm{Cd}(\mathrm{II})$ solutions in the $\mathrm{pH}$ range 1.0-6.3. The $\mathrm{pH}$ of the suspensions was changed using $0.1 \mathrm{M} \mathrm{HCl}$ or $0.1 \mathrm{M} \mathrm{NH}_{3} \cdot \mathrm{H}_{2} \mathrm{O}$. The static adsorption rates were studied with $20 \mathrm{~mL}$ of $70 \mu \mathrm{g} \cdot \mathrm{mL}^{-1} \mathrm{Cd}$ (II) 
solutions at $\mathrm{pH} 6.0$ from 5 to $70 \mathrm{~min}$. To measure the maximum adsorption capacity of MIIP and MNIP, the obtained MIIP (20 mg) and MNIP (20 mg) were added with $20 \mathrm{~mL} \mathrm{Cd(II)} \mathrm{solutions} \mathrm{containing}$ different initial concentrations $\left(30-80 \mu \mathrm{g} \cdot \mathrm{mL}^{-1}\right)$ at a constant temperature of $25^{\circ} \mathrm{C}$ for $35 \mathrm{~min}$. After complete adsorption, the adsorbent was collected with an external magnetic force, and the supernatant was introduced into the graphite furnace atomic absorption spectrometer for determining $\mathrm{Cd}(\mathrm{II})$ concentration. To assess the reusability of MIIP, $20 \mathrm{mg}$ MIIP was added into cadmium standard aqueous solution $\left(70 \mu \mathrm{g} \cdot \mathrm{mL}^{-1}\right)$ for a multiple adsorption-elution-adsorption process under the same conditions. The amount of $\mathrm{Cd}(\mathrm{II})$ bound by the polymer was calculated by the following equation:

$$
Q=\frac{\left(C_{0}-C_{\mathrm{e}}\right) \times V}{W}
$$

where $Q$ represents the amount of $C \mathrm{~d}(\mathrm{II})$ adsorbed $\left(\mathrm{mg} \cdot \mathrm{g}^{-1}\right), C_{0}$ and $C_{\mathrm{e}}$ are the initial and equilibrium concentration $\left(\mu \mathrm{g} \cdot \mathrm{mL}^{-1}\right)$ of $\mathrm{Cd}(\mathrm{II})$, respectively, $V$ is the volume of cadmium standard solution $(\mathrm{mL})$, and $W$ is the mass of sorbent $(\mathrm{g})$. All the tests were performed in triplicate.

To investigate the mechanism of the adsorption process, the Freundlich and Langmuir models were applied to fit the adsorption data. The Freundlich and Langmuir adsorption isothermal equations are as follows [24,25]:

$$
\begin{gathered}
\text { Freundlich model } \ln Q_{\mathrm{e}}=\ln K_{\mathrm{f}}+\frac{1}{n} \ln C_{\mathrm{e}} \\
\text { Langmuir model } \frac{C_{\mathrm{e}}}{Q_{\mathrm{e}}}=\frac{C_{\mathrm{e}}}{Q_{\mathrm{m}}}+\frac{1}{Q_{\max } k_{\mathrm{b}}}
\end{gathered}
$$

where $Q_{\mathrm{e}}$ is the equilibrium adsorption capacity $\left(\mathrm{mg} \cdot \mathrm{g}^{-1}\right), C_{\mathrm{e}}$ is the equilibrium concentration, $K_{\mathrm{f}}$ and $n$ are the Freundlich constants related to the adsorption capacity and intensity, respectively, $Q_{\max }$ represents the maximum adsorption capacity, and $K_{\mathrm{b}}$ is the Langmuir constant representing the affinity between the solute and adsorbent. To further understand the mechanism of the adsorption process, two different kinetic models (Laguerre pseudo-first-order and pseudo-second-order kinetic models) were used to fit the kinetic data. The two kinetic models for the adsorption of solid/liquid system are as follows [26,27]:

$$
\begin{gathered}
\text { Pseudo - first }- \text { order model }-\ln (1-F)=k_{\mathrm{a}} \mathrm{t} \\
\text { Pseudo - sec ond - order model } \frac{t}{Q_{\mathrm{t}}}=\frac{1}{k_{\mathrm{b}} Q_{\mathrm{e}}^{2}}+\frac{1}{Q_{\mathrm{e}}}
\end{gathered}
$$

where $F$ equals to $Q_{\mathrm{t}} / Q_{\mathrm{e}}, Q_{\mathrm{t}}$ and $Q_{\mathrm{e}}$ are the adsorption capacities of $\mathrm{Cd}(\mathrm{II})$ at time $t$ and at equilibrium, respectively, and $k_{\mathrm{a}}$ and $k_{\mathrm{b}}$ are the first order and second order rate constants, respectively.

The selective adsorption experiments of $\mathrm{Pb}(\mathrm{II}), \mathrm{Cu}(\mathrm{II})$, and $\mathrm{Ni}$ (II) ions with respect to $\mathrm{Cd}(\mathrm{II})$ ions were conducted using MIIP or MNIP sorbents. Briefly, $20 \mathrm{mg}$ of MIIP and MNIP sorbents were added to $20 \mathrm{~mL}$ of a binary mixture containing $20 \mathrm{mg} \cdot \mathrm{mL}^{-1} \mathrm{Cd}(\mathrm{II}) / \mathrm{Pb}(\mathrm{II}), \mathrm{Cd}(\mathrm{II}) / \mathrm{Cu}$ (II), or $\mathrm{Cd}(\mathrm{II}) / \mathrm{Ni}$ (II) at $\mathrm{pH} 6.0$ for $35 \mathrm{~min}$. The imprinting factor $(\alpha)$ and selectivity factor $(\beta)$ for $\mathrm{Cd}(\mathrm{II})$ ions relative to competing ions were calculated from the following equations:

$$
\begin{gathered}
\alpha=\frac{Q_{\mathrm{A}}}{Q_{\mathrm{B}}} \\
\beta=\frac{\alpha_{1}}{\alpha_{2}}
\end{gathered}
$$

where $Q_{\mathrm{A}}$ and $Q_{\mathrm{B}}$ represent adsorption capacities of metal ions onto MIIP and MNIP, respectively, and $\alpha_{1}$ and $\alpha_{2}$ are imprinting factors of $\mathrm{Cd}(\mathrm{II})$ and other ions.

\subsection{Real Sample Pretreatment}

To evaluate the practicability of MIIP for Cd(II) extraction from real samples with different matrices, rice 1 (Hunan, China), rice 2 (Heilongjiang, China), and rice 3 (Shandong, China) were 
selected. Because there were trace $\mathrm{Cd}(\mathrm{II})$ in the three rice samples, $0.5,1$, and $2 \mathrm{ng} \cdot \mathrm{mL}^{-1} \mathrm{Cd}(\mathrm{II})$ standard solutions were also spiked in the above rice samples.

The three spiked rice samples were subjected to acid digestion according to the previously published method [28]. Afterwards, $20 \mathrm{~mL}$ of digested solution was transferred into a $50 \mathrm{~mL}$ conical flask to form a dark cloudy suspension. Then, MIIP sorbent $(30 \mathrm{mg}$ ) was added into the sample solution after adjusting the $\mathrm{pH}$ to neutral. Extraction was achieved by shaking the sample solution for $35 \mathrm{~min}$. The sorbent was separated by a magnet, and the solution became clear. The sorbent was eluted with $2 \mathrm{M} \mathrm{HCl}$. After $8 \mathrm{~h}$, the supernatant was obtained, and the concentration of $\mathrm{Cd}$ (II) ion was determined by graphite furnace atomic absorption spectrometry.

\section{Results}

\subsection{Characterization}

The infrared spectra of $\mathrm{Fe}_{3} \mathrm{O}_{4}, \mathrm{Fe}_{3} \mathrm{O}_{4} @ \mathrm{SiO}_{2}, \mathrm{Fe}_{3} \mathrm{O}_{4} @ \mathrm{SiO}_{2}-\mathrm{C}=\mathrm{C}$, and MIIP are displayed in Figure 2. The adsorption peak at $589 \mathrm{~cm}^{-1}$ observed in all samples can be assigned to $\mathrm{Fe}-\mathrm{O}$ stretching vibrations, which indicated the presence of $\mathrm{Fe}_{3} \mathrm{O}_{4}$. These peaks intensity diminished as ion-imprinted polymer was layered onto $\mathrm{Fe}_{3} \mathrm{O}_{4}$ [29]. The peaks of $\mathrm{Fe}_{3} \mathrm{O}_{4} @ \mathrm{SiO}_{2}$ at 1100, 953, and $801 \mathrm{~cm}^{-1}$ corresponded to the $\mathrm{Si}-\mathrm{O}-\mathrm{Si}, \mathrm{Si}-\mathrm{O}-\mathrm{H}$, and $\mathrm{Si}-\mathrm{O}$ stretching, respectively, and indicated that the silica was modified onto the surface of $\mathrm{Fe}_{3} \mathrm{O}_{4}$ successfully. The peaks at 1603, 3063, and $3026 \mathrm{~cm}^{-1}$ coming from $\mathrm{C}=\mathrm{C}$ stretching suggested that the vinyl groups were grafted onto the surface of $\mathrm{Fe}_{3} \mathrm{O}_{4} @ \mathrm{SiO}_{2}$. The peak of MIIP at $1732 \mathrm{~cm}^{-1}$ was the characteristic group frequencies of the $\mathrm{C}=\mathrm{O}$ stretching vibration, and the appearance of the stretching vibrations at $1263 \mathrm{~cm}^{-1}$ belonging to $\mathrm{C}-\mathrm{N}-\mathrm{H}$ indicated that methacrylic acid and acrylamide were both involved in the imprinted polymerization.

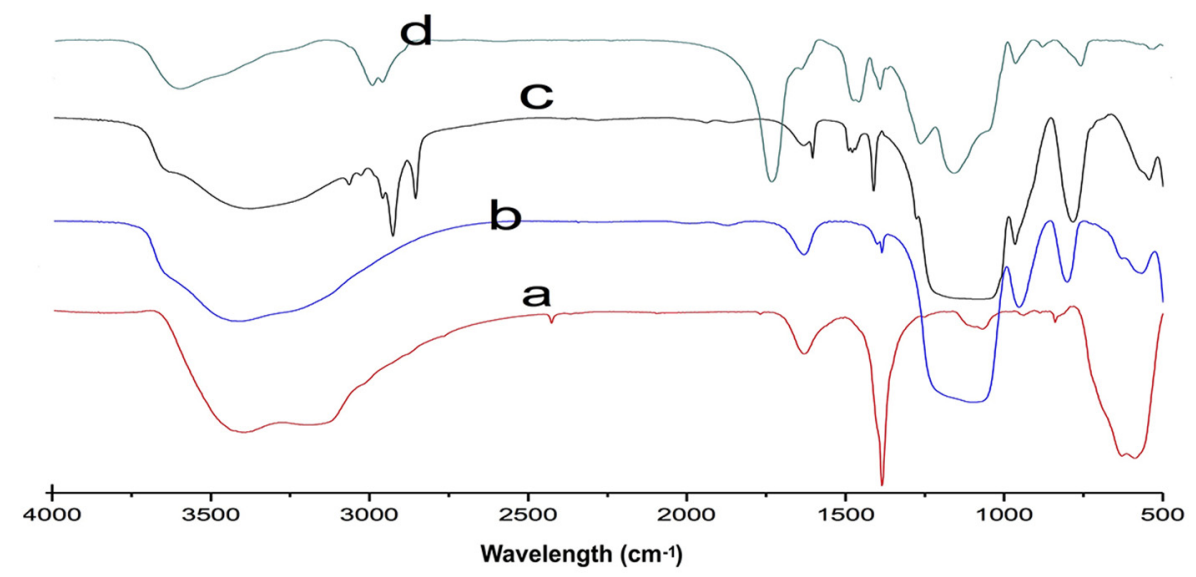

Figure 2. Fourier transform infrared (FT-IR) spectra of $\mathrm{Fe}_{3} \mathrm{O}_{4}(\mathbf{a}), \mathrm{Fe}_{3} \mathrm{O}_{4} @ \mathrm{SiO}_{2}$ (b), vinyl modified $\mathrm{Fe}_{3} \mathrm{O}_{4} @ \mathrm{SiO}_{2}$ (c) and MIIP (d).

Appropriate MIIP shell thickness enables easy access for the target ions and leads to higher adsorption capacity [30]. Figure 3 showed the morphology and microstructure of the $\mathrm{Fe}_{3} \mathrm{O}_{4}$ and MIIP. Magnetic $\mathrm{Fe}_{3} \mathrm{O}_{4}$ particles were spherical and uniform in size, with an average diameter of $20 \mathrm{~nm}$. After polymerization, the $\mathrm{Fe}_{3} \mathrm{O}_{4}$ particles were coated with a thick layer, and the surface was rough and irregular. The diameter of MIIP was larger compared with that of $\mathrm{Fe}_{3} \mathrm{O}_{4}$ and the thickness of the MIIP was about $100 \mathrm{~nm}$. The TEM micrograph observations confirmed that the imprinted layer was successfully immobilized on the surface of $\mathrm{Fe}_{3} \mathrm{O}_{4}$ particles.

The magnetic hysteresis loops of $\mathrm{Fe}_{3} \mathrm{O}_{4}$ and MIIP are illustrated in Figure 4. The two loops showed similar shapes and coercive force, which indicated that both of them were superparamagnetic in nature. The saturation magnetization of $\mathrm{Fe}_{3} \mathrm{O}_{4}$ was $55.6 \mathrm{emu} \cdot \mathrm{g}^{-1}$. In comparison, the MIIP showed a lower saturation magnetization, which was $4.88 \mathrm{emu} \cdot \mathrm{g}^{-1}$, suggesting the formation of the polymer 
layer on the surface of $\mathrm{Fe}_{3} \mathrm{O}_{4} @ \mathrm{SiO}_{2}$. Therefore, the magnetic separation of MIIP can be achieved with an external magnetic force.
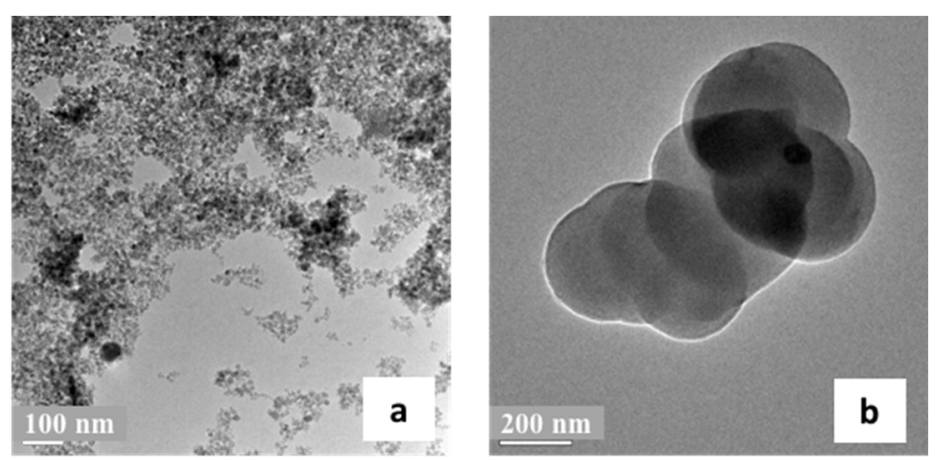

Figure 3. Transmission electron microscopy (TEM) images of $\mathrm{Fe}_{3} \mathrm{O}_{4}(\mathbf{a})$ and MIIP (b).

The thermogravimetric curves of MIIP and $\mathrm{Fe}_{3} \mathrm{O}_{4} @ \mathrm{SiO}_{2}$ have been established from room temperature $\left(25{ }^{\circ} \mathrm{C}\right)$ to $800{ }^{\circ} \mathrm{C}$. As shown in Figure 5, $\mathrm{Fe}_{3} \mathrm{O}_{4} @ \mathrm{SiO}_{2}$ exhibited weight loss of less than $16 \%$ during the whole process. MIIP had a slight weight loss of about $5 \%$ up to $300{ }^{\circ} \mathrm{C}$, which might be assigned to the physical evaporation of $\mathrm{H}_{2} \mathrm{O}$. The other loss (about $80 \%$ ) of mass of MIIP occurred between 300 and $600{ }^{\circ} \mathrm{C}$, and was attributed to the thermal decomposition of the organic component in the MIIP. The above results indicate that there is a thin imprinted layer on the surface of $\mathrm{Fe}_{3} \mathrm{O}_{4}$, which is in agreement with the observations from TEM and magnetism analysis. It also demonstrates that the sorbent prepared in this study has a good thermal stability, so it can be used in a wide temperature range.
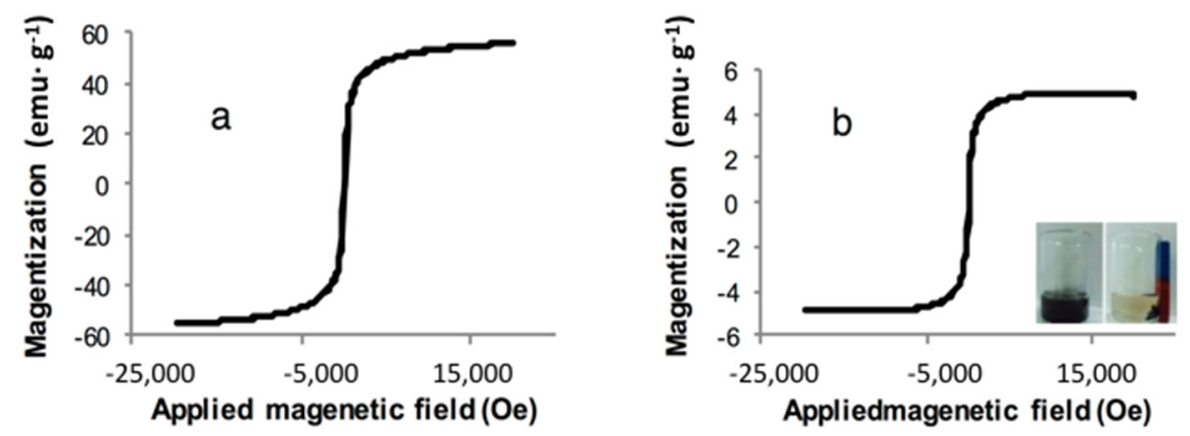

Figure 4. Magnetization hysteresis loops of $\mathrm{Fe}_{3} \mathrm{O}_{4}(\mathbf{a})$ and MIIP (b).

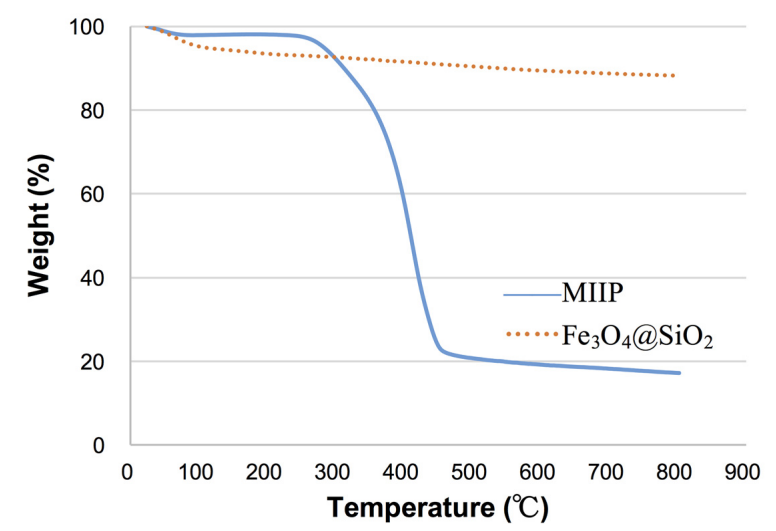

Figure 5. Thermal gravimetric analysis (TGA) curves of $\mathrm{Fe}_{3} \mathrm{O}_{4} @ \mathrm{SiO}_{2}$ and MIIP. 


\subsection{Adsorption Properties}

\subsubsection{Adsorption Capacity}

Adsorption capacity is an important indicator for the evaluation of the sorbent. Figure 6 showed the effect of the initial concentration of $\mathrm{Cd}(\mathrm{II})$ ion on the adsorption capacity. The adsorption amount of MIIP and MNIP increased with the increase of cadmium ion solution concentration within 30-80 $\mu \mathrm{g} \cdot \mathrm{mL}^{-1}$. The adsorption capacity of MIIP was higher than that of the MNIP under the same experimental concentration, suggesting that Cd(II)-MIIP had imprinted sites because of template ions added during synthesis. The maximum static adsorption capacities of the MIIP and MNIP for Cd(II) ion were 46.80 and $14.70 \mathrm{mg} \cdot \mathrm{g}^{-1}$, respectively. The fitting results for the Langmuir and Freundlich isotherms are shown in Figure 7. Compared with the Langmuir model, the Freundlich model was more suitable because of the value of the correlation coefficients $\left(R^{2}\right)$, which suggests that the adsorption of $\mathrm{Cd}(\mathrm{II})$ ion onto the MIIP was a multilayer adsorption, and the adsorption occurred on a heterogeneous surface with different active sites.

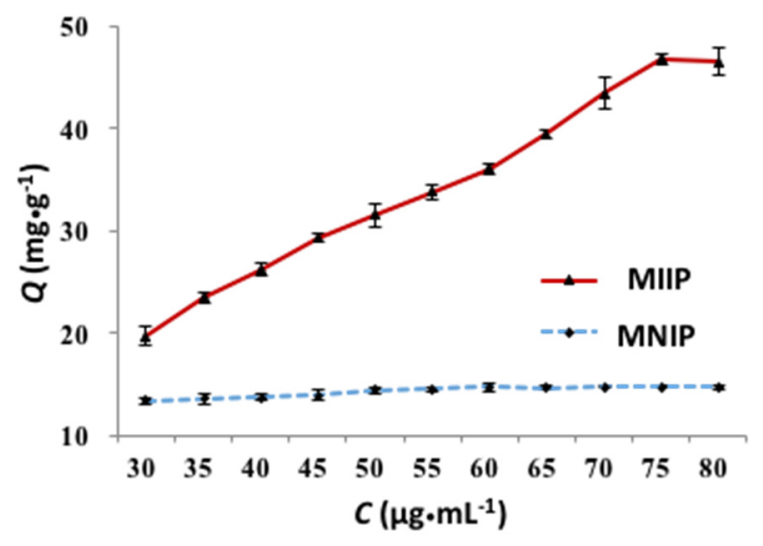

Figure 6. The effect of initial concentration on the adsorption capacity of MIIP and MNIP.
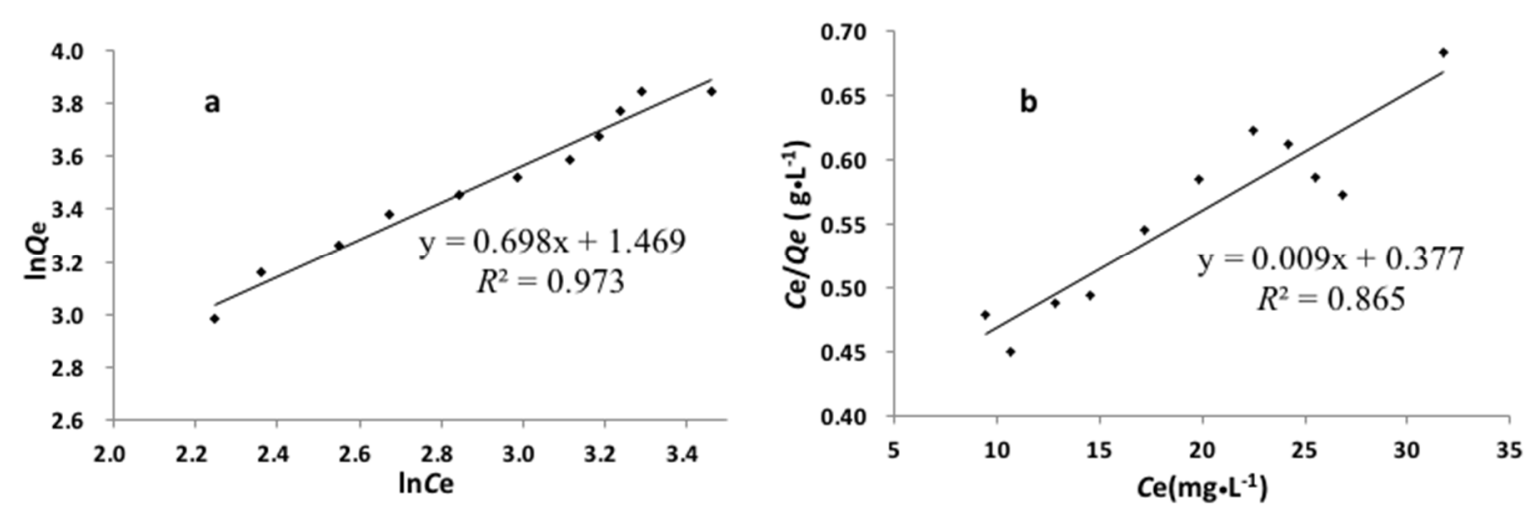

Figure 7. The fitting curves of Freundlich (a) and Langmuir (b) adsorption isotherm of MIIP.

\subsubsection{Adsorption Kinetics}

The effect of contact time on the adsorption capacity of $\mathrm{Cd}(\mathrm{II})$ ion on the MIIP in aqueous solution at $\mathrm{pH} 5.0$ at room temperature is presented in Figure 8. The amount of $\mathrm{Cd}$ ion uptake increased rapidly with the increase of contact time during the first $5 \mathrm{~min}$. From 5 to $35 \mathrm{~min}$, the adsorption amount increased slowly, and a plateau was reached with equilibrium. These results show that there were a large number of specific binding sites on the sorbent surface, which were available for the adsorption of Cd(II) at the early stage. Gradually, the specific binding sites were completely occupied. Furthermore, the adsorption kinetic curve of MNIP was similar to that of MIIP except that the saturated 
adsorption amount was lower. This difference in capacity was because the cavities left in the MIIP were complementary in size and shape to the template ion, whereas there were no imprinted sites in the MNIP.

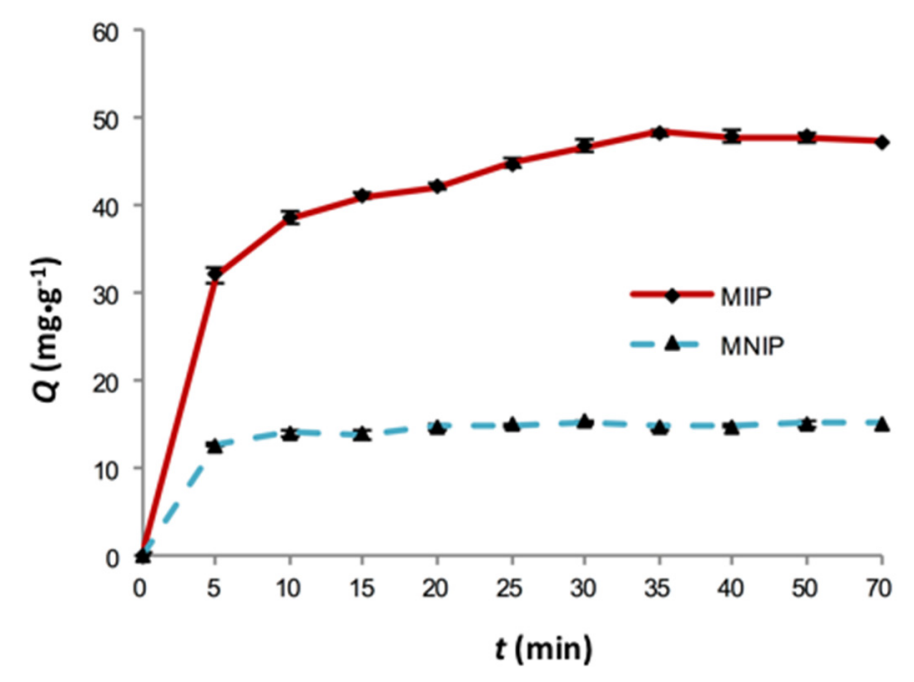

Figure 8. The adsorption dynamics curves of the MIIP and MNIP.

The corresponding linear regression correlation coefficients, $R^{2}$, were calculated from the linear plots of Equations (4) and (5) and are shown in Figure 9. The Lagergren pseudo-first-order kinetic model showed an $R^{2}$ average of 0.951 . However, the pseudo-second-order model showed a higher $R^{2}$ value (more than 0.99 ). In addition, the calculated $Q_{\mathrm{e}}$ values also agreed with the experimental data in the case of pseudo-second-order kinetics. The above results indicated that the pseudo-second-order kinetic model was more suitable to predict the adsorption process of $\mathrm{Cd}(\mathrm{II})$ onto MIIP.
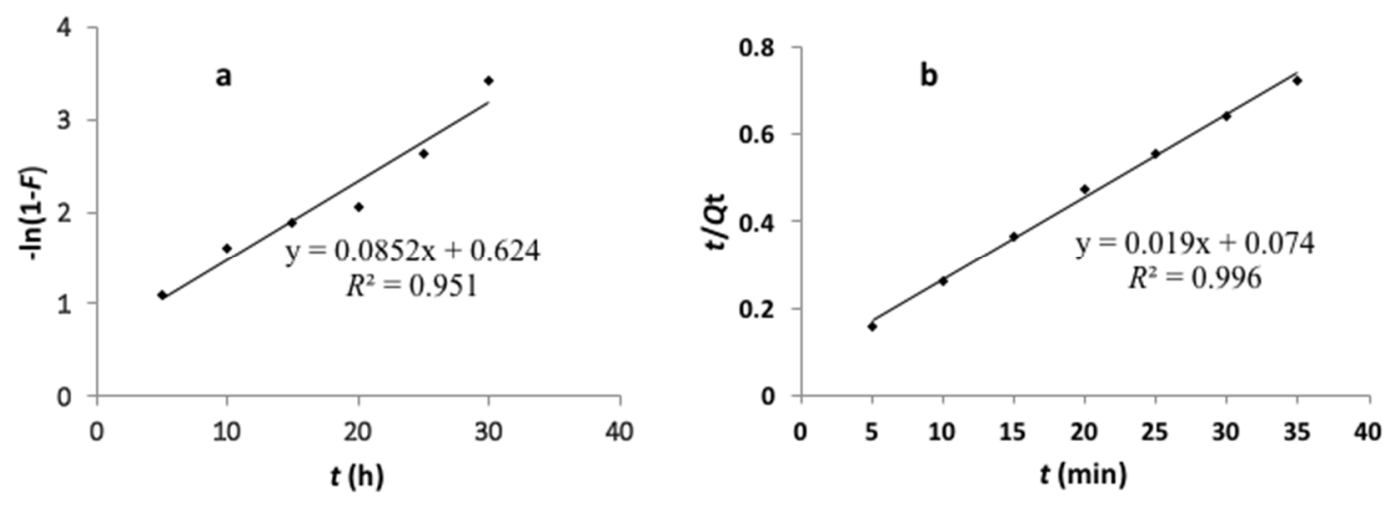

Figure 9. The linear plots of pseudo-first-order (a) and pseudo-second-order; (b) kinetic model.

\subsubsection{Selectivity Adsorption}

$\mathrm{Pb}(\mathrm{II}), \mathrm{Cu}(\mathrm{II})$, and $\mathrm{Ni}(\mathrm{II})$ ions were used as competitive metal ions because of their similar charge and ionic radius with $\mathrm{Cd}(\mathrm{II})$. Table 1 showed that the imprinting factors of $\mathrm{Cd}(\mathrm{II}), \mathrm{Pb}(\mathrm{II}), \mathrm{Cu}$ (II), and $\mathrm{Ni}(\mathrm{II})$ were $3.42,1.08,1.15$, and 1.33 , respectively. The selectivity factors of $\mathrm{Pb}$ (II), $\mathrm{Cu}$ (II), and $\mathrm{Ni}(\mathrm{II})$ were 3.17, 2.97, and 2.57, respectively. Figure 10 showed that MIIP exhibited a higher selectivity toward $\mathrm{Cd}(\mathrm{II})$ than other ions despite their similar size and charge in solution. Therefore, the high affinity, because of using template ions during imprinting, enabled the MIIP sorbent to extract Cd(II) selectively in the presence of other metal ions. 
Table 1. Selectivity of MIIP towards different metal ions.

\begin{tabular}{ccccc}
\hline Metal ions & $\boldsymbol{Q}_{\mathbf{A}}{\left.\mathbf{~} \mathbf{m g} \cdot \mathbf{g}^{-\mathbf{1}}\right)}$ & $\boldsymbol{Q}_{\mathbf{B}} \mathbf{( \mathbf { m g } \cdot \mathbf { g } ^ { - \mathbf { 1 } } )}$ & $\boldsymbol{\alpha}$ & $\boldsymbol{\beta}$ \\
\hline $\mathrm{Cd}(\mathrm{II})$ & 48.13 & 14.07 & 3.42 & - \\
$\mathrm{Pb}(\mathrm{II})$ & 14.13 & 13.13 & 1.08 & 3.17 \\
$\mathrm{Cu}(\mathrm{II})$ & 4.41 & 3.83 & 1.15 & 2.97 \\
$\mathrm{Ni}(\mathrm{II})$ & 4.95 & 3.72 & 1.33 & 2.57 \\
\hline
\end{tabular}

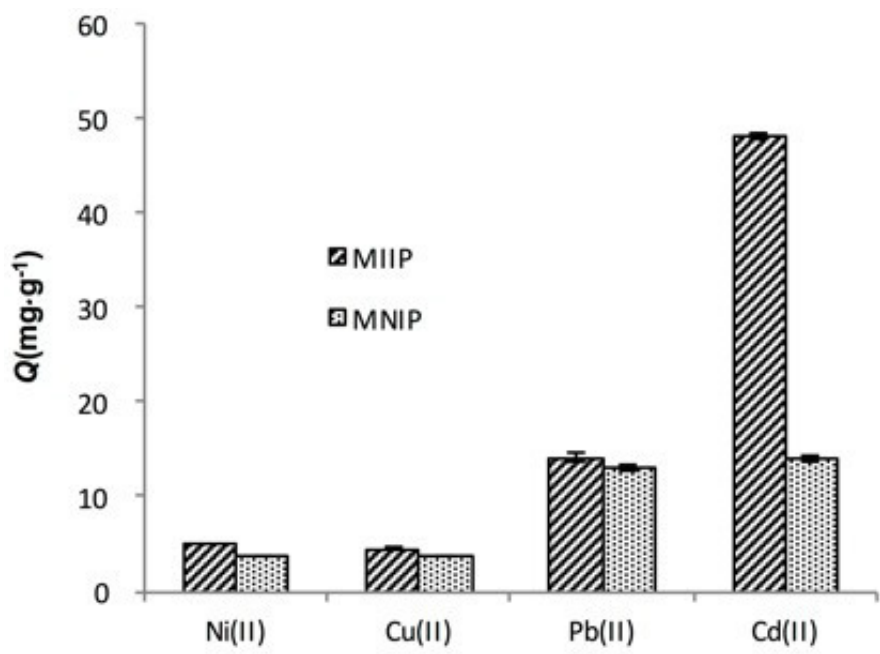

Figure 10. The adsorption capacities of $\mathrm{Cd}(\mathrm{II}), \mathrm{Pb}(\mathrm{II}), \mathrm{Cu}(\mathrm{II})$, and $\mathrm{Ni}(\mathrm{II})$ onto the MIIP and MNIP.

\subsection{Effect of Sample $p H$}

$\mathrm{pH}$ is one of the most important parameters for the adsorption performance of MIIP. The influence of different $\mathrm{pH}$ values in the range of 1.0-6.3 on the adsorption capacity of MIIP was studied, and the results are presented in Figure 11a. The results showed that the adsorption capacity increased quickly with the increase of $\mathrm{pH}$ value from 1.0 to 4.0 , and then remained constant in the $\mathrm{pH}$ range of 4.0-6.3. Because the positive charge on the surface of MIIP protonates binding sites, the affinity between MIIP and $\mathrm{Cd}(\mathrm{II})$ was weakened at low $\mathrm{pH}$ values, and a decrease in adsorption capacity was observed [26]. Thus, the optimum $\mathrm{pH}$ was 6.0 .

\subsection{Reusability}

The reusability and stability of MIIP were studied by eluting and reusing the same sorbent, and the adsorption results are presented in Figure 11b. As shown in Figure 11b, during the six adsorption-desorption cycles, there was no significant decrease in the adsorption capacity for $\mathrm{Cd}$ (II), and the recovery was higher than $90 \%$. The above results indicated that MIIP showed a stable regeneration adsorption efficiency and can be used repeatedly.
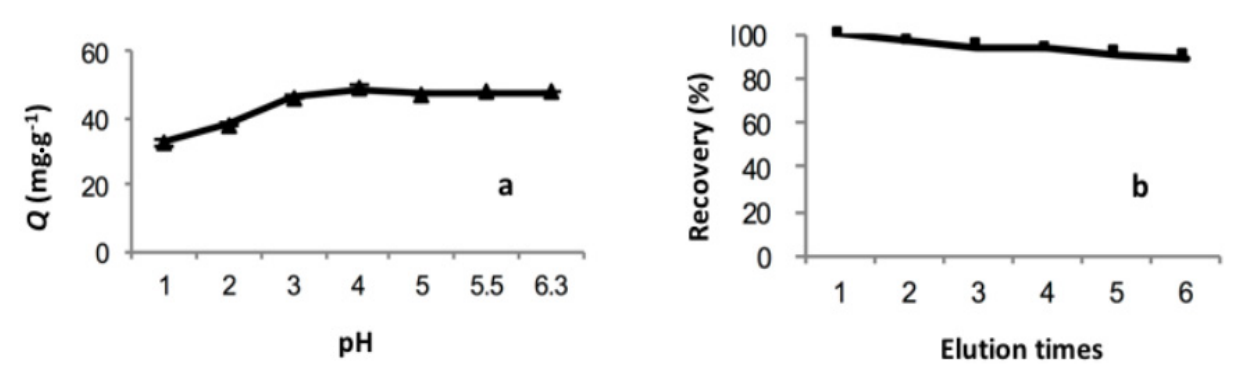

Figure 11. Effect of $\mathrm{pH}(\mathbf{a})$ and elution times; (b) on the adsorption capacity of MIIP. 


\subsection{Analytical Performance of the Method}

As shown in Table 2, the recoveries of Cd(II) ions from the real and spiked samples varied in the range of $80-103 \%$, and the relative standard deviation was less than $4.8 \%$. The limit of detection, defined as $C_{\mathrm{LOD}}=3 S_{\mathrm{b}} / m$, where $S_{\mathrm{b}}$ is the standard deviation of seven replicate blank signals and $m$ is the slope of the linear section of calibration curve after preconcentration for a sample volume of $50 \mathrm{~mL}$, was $0.05 \mu \mathrm{g} \cdot \mathrm{L}^{-1}$. In comparison with other reported Cd((II) IIPs for SPE extraction (Table 3), the proposed method shows comparable results in terms of analytical performance. The results support that the synthesized MIIP is a selective and reliable sorbent suitable for preconcentration and determination of $\mathrm{Cd}(\mathrm{II})$ ions at trace levels in real samples.

Table 2. The analysis results of Cd(II) ions in three spiked rice samples.

\begin{tabular}{ccccc}
\hline Sample & Added $\mathbf{n g} \cdot \mathbf{m L}^{\mathbf{- 1}}$ & Found $\mathbf{~ g} \cdot \mathbf{~ m L}^{-\mathbf{1}}$ & Recovery (\%) & RSD (\%) \\
\hline \multirow{3}{*}{ Rice 1 } & 0.5 & $0.41 \pm 0.09$ & 82 & 3.86 \\
& 1 & $0.86 \pm 0.11$ & 86 & 1.60 \\
& 2 & $1.87 \pm 0.16$ & 94 & 2.70 \\
\hline \multirow{2}{*}{ Rice 2 } & 0.5 & $0.49 \pm 0.10$ & 80 & 4.76 \\
& 1 & $0.94 \pm 0.13$ & 93 & 2.64 \\
Rice 3 & 2 & $2.06 \pm 0.15$ & 103 & 2.00 \\
& 0.5 & $0.40 \pm 0.06$ & 80 & 3.76 \\
& 1 & $0.91 \pm 0.10$ & 91 & 1.72 \\
\hline
\end{tabular}

Table 3. Comparison of analytical performance of different cadmium(II)-imprinted polymers used for SPE extraction.

\begin{tabular}{|c|c|c|c|c|c|c|c|c|}
\hline \multirow{2}{*}{$\begin{array}{l}\text { Monomer or } \\
\text { ligand }\end{array}$} & \multirow{2}{*}{$\begin{array}{c}\text { Detection } \\
\text { system }\end{array}$} & \multirow{2}{*}{$\begin{array}{c}\text { Adsorption } \\
\text { capacity }\left(\mathrm{mg} \cdot \mathrm{g}^{-1}\right)\end{array}$} & \multicolumn{3}{|c|}{ Selectivity factor } & \multirow{2}{*}{$\underset{\left(\mu \mathrm{g} \cdot \mathrm{L}^{-1}\right)}{\text { LOD }}$} & \multirow{2}{*}{ RSD (\%) } & \multirow{2}{*}{ Reference } \\
\hline & & & $P d$ & $\mathrm{Cu}$ & $\mathbf{N i}$ & & & \\
\hline $2-V^{a}$ & ICP-OES & 16.52 & N.R. & N.R. & N.R. & 0.14 & 2.6 & [31] \\
\hline $4-\mathrm{VP}^{\mathrm{b}}$ & FAAS & 0.48 & N.R. & N.R. & N.R. & 0.11 & 2.9 & [7] \\
\hline $\mathrm{ATU}^{\mathrm{c}}$ & ICP-AES & 38.30 & 9.46 & 2.86 & 6.42 & N.R. & N.R. & [32] \\
\hline TCPTS $^{d}$ & FAAS & 44.7 & 2.44 & 3.64 & N.R. & N.R. & N.R. & [33] \\
\hline $\mathrm{MAH}^{\mathrm{e}}$ & ICP-MS & 13.8 & 6.0 & 38.5 & 3.5 & 0.004 & 3.2 & [5] \\
\hline MAA $^{f},{ }^{\prime},{ }^{g}$ & GFAAS & 46.8 & 3.17 & 2.97 & 2.57 & 0.05 & 4.8 & This work \\
\hline
\end{tabular}

N.R. represents no reported; ${ }^{a}$ 2-Vinylpyridine; ${ }^{\mathrm{b}}$ 2-Vinylpyridine; ${ }^{\mathrm{c}}$ Allyl thiourea; ${ }^{\mathrm{d}}$ 3-thiocyanatopropyltriethox ysilane; ${ }^{\mathrm{e}} \mathrm{N}$-methacryloly-(L)-histidine; ${ }^{\mathrm{f}}$ Methacrylic acid; ${ }^{\mathrm{g}}$ Acrylamide.

\section{Conclusions}

The novel magnetic ion-imprinted polymers were successfully prepared with the utilization of dual functional monomers and were used as sorbents for the selective separation and preconcentration of trace $\mathrm{Cd}(\mathrm{II})$ ions. The MIIPs possessed high adsorption capacity and selectivity toward the template ion. The binding experimental data fit well into the Freundlich isotherm and match well with the pseudo-second-order kinetic model. After the sixth cycle of the adsorption-desorption process, the recovery remained higher than $90 \%$ that in the first cycle. Furthermore, the prepared sorbent possessed high adsorption capacity and selectivity toward the template ion. Good recoveries and a low limit of detection were obtained in the analysis of real rice samples. Because of the performance demonstrated in the present study, MIIP is an excellent candidate for the selective determination of $\mathrm{Cd}(\mathrm{II})$ in food and environmental samples.

Acknowledgments: This work was supported by the National Natural Science Foundation of China (No. 31501554), Guangdong Provincial Natural Science Foundation of China (2016A030310446), Guangdong Provincial Science and Technology Planning Project of China (2017A020208059), China Scholarship Council Scholarship (201607630008). 
Author Contributions: Xiaoyan Xu and Xingguo Tian conceived and designed the experiments; Mei Wang performed the experiments and analyzed the data; Zhenlin Xu and Qing Wu contributed reagents/materials / analysis tools; Xiaoyan Xu and Mei Wang wrote the paper.

Conflicts of Interest: The authors declare no conflict of interest.

\section{References}

1. Fan, H.T.; Li, J.; Li, Z.C.; Sun, T. An ion-imprinted amino-functionalized silica gel sorbent prepared by hydrothermal assisted surface imprinting technique for selective removal of cadmium (II) from aqueous solution. Appl. Surf. Sci. 2012, 258, 3815-3822. [CrossRef]

2. Zhu, F.; Li, L.; Xing, J. Selective adsorption behavior of Cd (II) ion-imprinted polymers synthesized by microwave-assisted inverse emulsion polymerization: Adsorption performance and mechanism. J. Hazard. Mater. 2017, 321, 103-110. [CrossRef] [PubMed]

3. Vainio, H.; Heseltine, E.; Partensky, C.; Wilbourn, J. Meeting of the IARC working group on beryllium, cadmium, mercury and exposures in the glass manufacturing industry. Scand. J. Work Environ. Health 1993, 19, 360-363.

4. Xie, F.; Lin, X.; Wu, X.; Xie, Z. Solid phase extraction of lead (II), copper (II), cadmium (II) and nickel (II) using gallic acid-modified silica gel prior to determination by flame atomic absorption spectrometry. Talanta 2008, 74, 836-843. [CrossRef] [PubMed]

5. Yilmaz, V.; Yilmaz, H.; Arslan, Z.; Leszczynski, J. Novel imprinted polymer for the preconcentration of cadmium with determination by inductively coupled plasma mass spectrometry. Anal. Lett. 2017, 50, 482-499. [CrossRef] [PubMed]

6. Krystofova, O.; Trnkova, L.; Adam, V.; Zehnalek, J.; Hubalek, J.; Babula, P.; Kizek, R. Electrochemical microsensors for the detection of cadmium (II) and lead (II) ions in plants. Sensors 2010, 10, 5308-5328. [CrossRef] [PubMed]

7. Gawin, M.; Konefał, J.; Trzewik, B.; Walas, S.; Tobiasz, A.; Mrowiec, H.; Witek, E. Preparation of a new Cd (II)-imprinted polymer and its application to determination of cadmium (II) via flow-injection-flame atomic absorption spectrometry. Talanta 2010, 80, 1305-1310. [CrossRef] [PubMed]

8. Khoddami, N.; Shemirani, F. A new magnetic ion-imprinted polymer as a highly selective sorbent for determination of cobalt in biological and environmental samples. Talanta 2016, 146, 244-252. [CrossRef] [PubMed]

9. Dakova, I.; Karadjova, I.; Georgieva, V.; Georgiev, G. Ion-imprinted polymethacrylic microbeads as new sorbent for preconcentration and speciation of mercury. Talanta 2009, 78, 523-529. [CrossRef] [PubMed]

10. Asgharinezhad, A.A.; Jalilian, N.; Ebrahimzadeh, H.; Panjali, Z. A simple and fast method based on new magnetic ion-imprinted polymer nanoparticles for the selective extraction of $\mathrm{Ni}$ (II) ions in different food samples. RSC Adv. 2015, 5, 45510-45519. [CrossRef]

11. Zhang, Z.; Dai, S.; Hunt, R.D.; Wei, Y.; Qiu, S.L. Ion-Imprinted Zeolite: A Surface Functionalization Methodology Based on the "Ship-in-Bottle" Technique. Adv. Mater. 2001, 13, 493-496. [CrossRef]

12. Ramakrishnan, K.; Prasada Rao, T. Ion-imprinted polymer solid phase extraction (IIP-SPE) for preconcentrative separation of erbium (III) from adjacent lanthanides and yttrium. Sep. Sci. Technol. 2006, 41, 233-246. [CrossRef]

13. Behbahani, M.; Hassanlou, P.G.; Amini, M.M.; Moazami, H.R.; Abandansari, H.S.; Bagheri, A.; Zadeh, S.H. Selective solid-phase extraction and trace monitoring of lead ions in food and water samples using new lead-imprinted polymer nanoparticles. Food Anal. Methods 2015, 3, 558-568. [CrossRef]

14. Ghorbani-Kalhor, E.; Behbahani, M.; Abolhasani, J. Application of Ion-imprinted polymer nanoparticles for selective trace determination of palladium ions in food and environmental samples with the aid of experimental design methodology. Food Anal. Methods 2015, 7, 1746-1757. [CrossRef]

15. Saraji, M.; Yousefi, H. Selective solid-phase extraction of Ni (II) by an ion-imprinted polymer from water samples. J. Hazard Mater. 2009, 167, 1152-1157. [CrossRef] [PubMed]

16. Luo, X.B.; Luo, S.L.; Zhan, Y.C.; Shu, H.Y.; Huang, Y.N.; Tu, X.M. Novel Cu (II) magnetic ion-imprinted materials prepared by surface imprinted technique combined with a sol-gel process. J. Hazard. Mater. 2011, 192, 949-955. [CrossRef] [PubMed] 
17. Ebrahimzadeh, H.; Moazzen, E.; Amini, M.M.; Sadeghi, O. Novel magnetic ion-imprinted polymer as a highly selective sorbent for extraction of gold ions in aqueous samples. Anal. Methods 2012, 4, 3232-3237. [CrossRef]

18. Sadeghi, O.; Aboufazeli, F.; Zhad, H.R.L.Z.; Karimi, M.; Najafi, E. Determination of Pb (II) ions using novel ion-imprinted polymer magnetic nanoparticles: Investigation of the relation between $\mathrm{Pb}$ (II) ions in cow's milk and their nutrition. Food Anal. Methods 2013, 6, 753-760. [CrossRef]

19. Sayar, O.; Torbati, N.A.; Saravani, H.; Mehrani, K.; Behbahani, A.; Zadeh, H.R.M. A novel magnetic ion-imprinted polymer for selective adsorption of trace amounts of lead (II) ions in environment samples. J. Ind. Eng. Chem. 2014, 20, 2657-2662. [CrossRef]

20. Cai, X.Q.; Li, J.H.; Zhang, Z.; Yang, F.F.; Dong, R.C.; Chen, L.X. Novel $\mathrm{Pb}^{2+}$ ion-imprinted polymers based on ionic interaction via synergy of dual functional monomers for selective solid-phase extraction of $\mathrm{Pb}^{2+}$ in water samples. ACS Appl. Mater. Interface 2013, 6, 305-313. [CrossRef] [PubMed]

21. Massart, R. Preparation of aqueous magnetic liquids in alkaline and acidic media. IEEE. Trans. Magn. 1981, 17, 1247-1248. [CrossRef]

22. Aboufazeli, F.; Zhad, H.R.L.Z.; Sadeghi, O.; Karimi, M.; Najafi, E. Novel ion-imprinted polymer magnetic mesoporous silica nano-particles for selective separation and determination of lead ions in food samples. Food Chem. 2013, 141, 3459-3465. [CrossRef] [PubMed]

23. Xie, L.W.; Guo, J.F.; Zhang, Y.P.; Hu, Y.C.; You, Q.P.; Shi, S.Y. Novel molecular imprinted polymers over magnetic mesoporous silica microspheres for selective and efficient determination of protocatechuic acid in Syzygium aromaticum. Food Chem. 2015, 178, 18-25. [CrossRef] [PubMed]

24. Freundlich, H.M.F. Über die adsorption in lösungen. Z. Phys. Chem. 1906, 57, 385-470. [CrossRef]

25. Langmuir, I. The adsorption of gases on plane surfaces of glass, mica and platinum. J. Am. Chem. Soc. 1918, 40, 1361-1403. [CrossRef]

26. Lagergren, S. About the theory of so-called adsorption of soluble substances. K. Sven. Vetensk. Handl. 1898, 24, 1-39.

27. Ho, Y.S.; McKay, G. Pseudo-second-order model for sorption processes. Process Biochem. 1999, 34, 451-465. [CrossRef]

28. Dos Santos, W.N.; Cavalcante, D.D.; Macedo, S.M.; Nogueira, J.S.; Da Silva, E.G. Slurry sampling and HG AFS for the determination of total arsenic in rice samples. Food Anal. Methods 2013, 6, 1-5. [CrossRef]

29. Zhang, M.L.; Zhang, Z.H.; Liu, Y.N.; Yang, X.; Luo, L.J.; Chen, J.T.; Yao, S.Z. Preparation of core-shell magnetic ion-imprinted polymer for selective extraction of $\mathrm{Pb}$ (II) from environmental samples. Chem. Eng. J. 2011, 178, 443-450. [CrossRef]

30. Kang, R.F.; Qiu, L.; Fang, L.L.; Yu, R.P.; Chen, Y.; Lu, X.; Luo, X.B. A novel magnetic and hydrophilic ion-imprinted polymer as a selective sorbent for the removal of cobalt ions from industrial wastewater. J. Environ. Chem. Eng. 2016, 4, 2268-2277. [CrossRef]

31. Ashouri, N.; Mohammadi, A.; Hajiaghaee, R.; Shekarchi, M.; Khoshayand, M.R. Preparation of a new nanoparticle Cd (II)-imprinted polymer and its application for selective separation of cadmium (II) ions from aqueous solutions and determination via inductively coupled plasma optical emission spectrometry. Desalin. Water Treat. 2016, 57, 14280-14289. [CrossRef]

32. Li, M.; Feng, C.G.; Li, M.Y.; Zeng, Q.X.; Gan, Q.; Yang, H.Y. Synthesis and characterization of a surface-grafted Cd (II) ion-imprinted polymer for selective separation of Cd (II) ion from aqueous solution. Appl. Surf. Sci. 2015, 332, 463-472. [CrossRef]

33. Li, Z.C.; Fan, H.T.; Zhang, Y.; Chen, M.X.; Yu, Z.Y.; Cao, X.Q.; Sun, T. Cd (II)-imprinted polymer sorbents prepared by combination of surface imprinting technique with hydrothermal assisted sol-gel process for selective removal of cadmium (II) from aqueous solution. Chem. Eng. J. 2011, 171, 703-710. [CrossRef]

(C) 2017 by the authors. Licensee MDPI, Basel, Switzerland. This article is an open access article distributed under the terms and conditions of the Creative Commons Attribution (CC BY) license (http://creativecommons.org/licenses/by/4.0/). 